\title{
The Last Farewell Embrace: Spirituality, Near-Death Experiences and Other Extraordinary Events Among Nurses*
}

\author{
Paulo Nuno Martins \\ Centre Internationale de Recherche et d'Études Transdisciplinaire (CIRET), Paris, France \\ Transdisciplinary Center for Studies of Consciousness (CTEC), Oporto, Portugal \\ Interuniversity Center of History of Science and Technology (CIUHCT), Lisbon, Portugal
}

\begin{abstract}
This recension to the book of Alejandro Parra aims to be a contribution on the various topics that the theme on the experiences in "threshold of death" addresses, namely, paranormal phenomena experienced by several people, such as the nurses, and that are impossible to be explained within the current biomedical model. In this sense, the study of the concept of spirituality in health care could be an important topic to be approached in this area of research with the purpose of better understanding the patients who are in the process of "passing", as well as expand the perspective of the current biomedical model, so as to take into consideration the human being in its various dimensions: spiritual, psychological, and physical/biological.
\end{abstract}

Keywords: experiences at the threshold of death, paranormal phenomena, the role of spirituality

\section{Introduction}

The present work published by Gradiva was part of a project supported by the BIAL Foundation of Portugal (Grant 246/14) and the Society for Psychical Research of London, and that allowed the author to publish in Portugal a summary of several paranormal phenomena which were experienced by different people related to patients at the threshold of death, and that are inexplicable by current scientific knowledge. These kinds of experiences are described by some health care providers and nurses who experienced them in Intensive Care Units, Neonatology, Pediatrics, and Neuropsychiatry.

As a researcher in epistemology of science (Centre Internationale de Recherche et d'Études Transdisciplinaire [CIRET], Transdisciplinary Center for Studies of Consciousness [CTEC], and Interuniversity Center of History of Science and Technology [CIUHCT]) whose area of investigation encompasses the search for an integrative medicine model—study the human being in a holistic way—has made this theme particularly interesting to me. In fact, I think that it might contribute to expand the perspectives provided by the current model of conventional medicine, which needs to include a panoply of paranormal phenomena that has occurred at the threshold of death, namely, near death experiences (NDE), out-of-body experiences (OBE), spontaneous cures,

\footnotetext{
${ }^{*}$ Book Review of Parra, Alejandro. (2019). O Último Abraço: Fenómenos paranormais no limiar da morte. Gradiva Publicações (Original title: El Último Abrazo de Despedida: Espiritualidad, experiencias cercanas a la morte y otros eventos extraordinarios en enfermeras).

Paulo Nuno Martins, Ph.D., Researcher, Centre Internationale de Recherche et d'Études Transdisciplinaire (CIRET), Paris, France; Transdisciplinary Center for Studies of Consciousness (CTEC), Oporto, Portugal; Interuniversity Center of History of Science and Technology (CIUHCT), Lisbon, Portugal.
} 
among others unusual clinical situations, some of them verified in a religious context. In this sense, this book presents a great merit, since the author was able to approach a subject of great complexity with a deep historical rigor, in the psychological and spiritual perspectives, evidencing his academic formation. Dr. Alejandro Parra has a Master degree (UAI) and Ph.D. (UCES) in Psychology, and he carries out his professional activity as a psychotherapist, professor, and researcher of Psychology at the Aberta Interamericana University of Buenos Aires. He is also president of the Paranormal Psychology Institute and the Latin American Information Agency.

\section{Methods}

In this book review, seven references were chosen in order to contribute to the improvement of of the topics covered on the theme described by the author of this book.

\section{Results and Discussion}

The thematic content is very well-structured and organized because it describes the various items very clearly and elegantly. The book begins with a "Preface" (pp. 9-11) written by Professor Dr. Mário Simões who suggests that knowledge on this subject "should be part of the Curriculum of the courses of health professionals, namely physicians and nurses, and even ministers of the various religions, especially if they work in palliative care". On the other hand, the author frames the theme in the "Introduction" of the book (pp. 13-21), referring to the topics of the various chapters, pointing out that the main objective of the book is "to be the beginning of a personal search during which the reader could develop his own ideas and interpretations about death and dying".

In Chapter 1 of the book (pp. 23-30), the author refers very elegantly to "spiritual health in nursing practice" distinguishing between spirituality and religion, and their relation to health, namely, faith, meditation, prayer as tools to reduce stress, addictions, and so on. In this sense, the author points out that nowadays the programs in clinical psychology, psychiatry, and psychotherapeutic practice hardly address the theme of spirituality. In this regard, the current research study could have mentioned some practical cases that might show the need and the advantages of science and spirituality to be approached together, namely in the training of health care professionals, in relation to experiences at the threshold of death. For example, we can read an objective description of a NDE reported by the neurosurgeon Eben Alexander (2013) ${ }^{1}$, who was initially skeptical of all spiritual experiences and in favor of exclusively scientific "logic alone" approach, although his own NDE led himself to question his personal perspective on this subject in medical practice:

I am a neurosurgeon.... On November 10, 2008, I was surprised by a rare disease and I was in a coma for seven days. In that period, my entire neocortex - the outer surface of the brain that makes us human-became paralyzed.... When our brain is absent, we are also absent. As a neurosurgeon, I have heard many reports of people having had strange experiences, usually after suffering heart attacks: travel stories to mysterious and wonderful places, conversations with dead relatives-and even encounters with God. Fascinating, no doubt, but all this, in my opinion, was pure fantasy. After all, what triggered the supernatural experiences that people reported so often? In fact, the answer did not interest me, but I believed that those experiences had a brain base. All consciousness has. If there is no brain activity, there is no awareness. This is because the brain is the machine that produces consciousness. When the machine fails, consciousness stops.... During the coma, my brain did not work inadequately—it just did not work. Today, I believe it was responsible for the depth and intensity of the NDE that I experienced in that period.... I got to know a dimension of consciousness that existed completely apart from the limitations of my physical brain. In a way, I experienced an avalanche of NDE.

As a neurosurgeon, with decades of research and practice, I was in a better position to assess not only the reality but

\footnotetext{
${ }^{1}$ The translation into English is my responsibility.
} 
the implications of what had happened. And those implications are extraordinary. My experience has shown me that the death of body and brain is not the end of consciousness, and that human existence continues after death. And more importantly, it perpetuates itself under the gaze of a God who loves us and who cares about each of us, the destiny of the Universe and all the beings contained in it.... But it is a very delicate theme because it is too strange for "linear" understanding. In addition, the conclusions are based on a medical analysis of my experience and my familiarity with the most advanced concepts on neuroscience and studies of consciousness.

In this regard, Dr. Raymond Moody said that "Dr. Eben Alexander's near death experience (NDE) is the most impressive that I have heard in more than four decades of study on this phenomenon".

The Chapter 2 (pp. 31-52) and Chapter 3 of the book (pp. 53-80), which the author called respectively "When the end is only the beginning: Experiences in palliative care" and the "Transforming experiences of 'sensitive nurses"” are from my point of view interconnected between them. The author describes these two chapters very clearly, having given in Chapter 2 several examples of physical phenomena related to experiences of patients at the threshold of death, particularly described by palliative care nurses, while Chapter 3 refers to "A survey of 510 nurses from the Buenos Aires Health Unit" which were divided between those who received reports of near-death experiences and anomalous-paranormal phenomena from various sources, namely other colleagues, family members of patients, physicians, people in the hospital unit and, on the other hand, those in the control group who had no experience of this type. Thus, within the group of nurses who experienced paranormal phenomena, these are characterized by the typical NDE, OBE some of them accompanied by experiences of "connection" between the transcendent and the physical reality. In this regard, some hypotheses could have been suggested by the author in order to contribute to the understanding of these phenomena at the threshold of death, which includes the study of Quantum Physics, and the concept of non-locality, as well as some brain-mind models, that might include the explanation of spiritual realities or non-tangible dimensions. For example, the following article (Martins, 2019) ${ }^{2}$ describes the importance of the relation between quantum physics and psychology in the study of patients at the threshold of death:

In Western culture, the physicist Basarab Nicolescu argues that "there are different levels of reality and therefore different levels of perception" in which each level is characterized by its "incompleteness" according to Gödel's Theorem, where the perception of each level of reality is only part of the Totality or Consciousness One. In the same way, Eastern culture also argues that human beings have the possibility of accessing several "levels of perception" according to the "Panchakoshas Theory"....

Furthermore, Indian philosophies argue that "everything begins in the Consciousness One" or the Source of Life, which is independent of matter, that is, the Consciousness One is the basis of all beings. So, based on this point of view, the physicist Amit Goswami proposes a model of the human being where the Soul and the "quantum body" (body that survives after death, and contains the experiences lived during the life) exist on a level of reality-the transcendent-while the physical body manifests itself on another level of reality-the physical.... Amit Goswami adds that self-aware beings have a "classical mind-brain" component and a "quantum mind-brain" component (according to Hameroff and Penrose). When the human being reincarnate again and a given sensorial stimulus arrives to him, then the "classic mind-brain" component processes the information. So, the human being has the freedom to choose between the old standards of life and the new patterns of behaviour, which are recorded by the "quantum mind-brain" component. When the "classical mind-brain" component dies, it disappears along with the physical body, while the "quantum mind-brain" component survives (being part of the "quantum body"), and it is this "quantum body" that will determine the number of subsequent reincarnations of the conscious being.... Another example (related with this theme) is that of Edgar Cayce who was able to describe the past lives of several people through what he called the "Akashic Memory" which could be interpreted as a "non-local" reincarnational memory (of the "quantum body") into a transcendent reality. The Soul (which connects the

\footnotetext{
${ }^{2}$ Idem.
} 
various incarnations of a person) is always the same and thus a "sensitive" person (able to "see" the Soul) might have access to that person's past lives.

In Chapter 4 (pp. 81-95) and the Chapter 5 (pp. 97-109) of the book, which the author designed, respectively, as "Windows for the beyond: The dreams and the visions of the end of life" and "End-of-life experiences in elderly homes" are also from my point of view interconnected between them. The author described these two chapters in a detailed and pertinent way, having referred to in Chapter 4, some phenomena related to the end of patient's life, such as experiences associated with a particular spiritual connection or simply the comforting presences of loved ones waiting for the patient in the transition phase from life to death, who might help him to solve his outstanding questions in the Earth. Furthermore, in Chapter 5, the author mentioned some experiences related with this topic, such as thermal changes, visions of children or loved ones, vision of "energy fields", the presence of animals that sense the end of the patient's life, among others. In this regard, the author could have referred to the area of spiritual hypnotherapy, for example described in the book Destiny of Souls (Newton, 2000) in order to give to the reader a wider perspective of the "spiritual side of the human being"for patients who are about to "depart" from Earth, and who "see" what they have performed during their life on Earth, and that goes beyond mere "hallucinations on the deathbed". For example, we can read in the book suggested before:

At the moment of death, our soul rises out of its host body. If the soul is older and has experience from many former lives, it knows immediately it has been set free and is going home.

However, most souls I have been worked with are met by guides just outside Earth's astral plane...time has no meaning in the spiritual world.... Disincarnated who choose to comfort someone who is grieving, or have other reasons to stay near the place of their deathbed for a while, experience no sense of time loss. This becomes now time for the soul as opposed the linear time.... In the early stages of their exit, all souls encounter a "wispy cloudiness" around them that soon becomes clear, enabling them to look off into a vast distance. This is the moment when the average soul sees a ghostly form of energy coming toward them. This figure may be a loving soulmate, but more often it is our guide. In circumstances where we are met by a partner or friend who has passed on before us, our guide is also close to us, so that he can help us in the process of "passing through"... The soul has such majesty that it is beyond description. I tend to think of souls as intelligent light forms of energy.... The energy of the soul is able to divide into identical parts, similar to a hologram....and intends to be subjected to an initial debriefing session with gentle and caring teacher-guides. The meeting may be long or short depending upon the circumstances of what we did or did not accomplish with regard to our life contract. Special karmic issues are also reviewed...those souls who have been associated with evil are taken to special centers which some clients call "intensive care units". Here, their energy is remodeled to make it whole again....

The Chapter 6 (pp. 111-122) and Chapter 7 (pp. 123-140) of the book, which the author referred to as, respectively, "Near-death experiences as an end-of-life event" and "Spirituality in the visions of those who are dying" are also interconnected with each other according to my point of view. These topics are very well described in Chapter 6 because the author referred to some sensations described by patients who underwent NDE, such as the sensation of floating, seeing a figure at the end of the tunnel, the feeling of inner peace and decreased fear of death, whereas in Chapter 7, some hypothesis are posed whether these experiences are extra-human (spiritual) dimensions or mere (psychological) hallucinations. In this regard, this book could have pointed out that in scientific terms, it can no longer be said that mind and consciousness depend exclusively of the brain and physical body in order to remain in operation, as referred to in the book (Domingos, Loução, \& Dias, 2009)

Preface (Mário Simões).... I remember the first time, I heard about the Near Death Experiences (NDEs). I was in

3 Idem. 
Cambridge, in 1992, at a conference of the Scientific and Medical Network. Peter Fenwick (neuropsychiatrist and neurophysiologist) presented his studies on NDEs. I was struck by the amount of data that attested to various aspects and that the course of time only came to sediment: 1 . The human brain does not function during a cardiac arrest; 2 . The mind and consciousness can continue to function during that period; 3. Regardless of ethnicity, geographic location, epidemiological data, age, sex or time period, the NDE descriptions were, in essence, always the same....

It seems, therefore, that explanations referring only to reductive explanations of NDEs, as being the result of physical and chemical alterations of the brain, is not enough, unless it is admitted that self-suggestion (hypnosis is self-hypnosis) is susceptible to promote those changes... The problem becomes more complex in view of the above data. Are we then dealing with a phenomenon of consciousness and this would be a subtle, independent instance of the whole or in part of the brain? Could it be a program with which we were born, which is "turned on" whenever we find ourselves in a situation of real or imagined near death experience? Would it be an "engram" (foundation of memory) in order to remind us of the "divine origin" of our essence, as many people point out, particularly the followers of the transcendental theories? It seems therefore that in the current state of science and without involving a definitive causal explanation, it seems that there are correlation between experiential states and specific psycho-physiologies. We find ourselves at a point where we can conclude that none of the current, organic, psychological, or transcendental theories per se explains NDEs.

In this regard, the cardiologist and scientist Pim van Lommel considers that there is no exclusively physical explanation for the phenomenon of NDEs, and his studies were published in the Lancet. Carl Jung also argued that NDEs are something real, "wholly objective" and not the product of fantasy or hallucination, opening up the possibility of "another side of life" where the consciousness might continue to exist after death.

The Chapter 8 (pp. 141-153) of the book which the author mentioned to as "Death and dying: palliative care and spirituality" summarizes the topic of palliative care which includes the medical interventions related with the pharmacological, psychological, social, and spiritual treatments of both the patient who is about to leave Earth, as well as their relatives who might require specific support (psychological) from health care professionals. The author refers very opportunely to Kendall's "holistic biomedical model" and Paterson and Zderad's "humanistic biomedical model" for the study of terminal patient care. In this regard, the present study could also have referred to these "models of integrative medicine" along with the assumptions of the philosophies of Ancient wisdom, such as "Theories of Reincarnation" where it is suggested that the subject's soul survives after death which might be a source of consolation for those who have undergone through this difficult experience. For example, this topic is described in the following book (Tucker, 2005), where it is referred:

For more than 40 years, researchers have investigated their reports. More than 2,500 cases are registered in the files of the Division of Personality Studies at the University of Virginia. Some of the children have said they were deceased family members, and others described previous lives as strangers. In a typical case, a very young child begins to describe memories of another life. This child is persistent about this and often demands to be taken to his other family in another location. When the child has given names or enough details about the other location, the family often goes there to find if the child's statements fit to the life of a person who has died in the recent past.... More specifically, the idea of being able to come back and to try again may appeal to a lot of people.

We cannot change the mistakes we have made in the past, but being able to try to do better the next life, it would certainly be a comfort.... Life Before Life is therefore analytical rather than emotional or religious.... These cases are not about "proof", they are about evidence.

In this regard, I have to mention that this theme is extensively covered by the pioneer scientist in this field, Ian Stevenson who wrote the Prologue of the book referred to above and who addresses the topic of reincarnation, "as the best explanation-although not the only one-for the cases investigated".

In the "Epilogue" (pp. 157-161), the author refers to the need for health professionals to receive appropriate 
spiritual training in order to distinguish between a "pre-terminal delirium" and a "spiritual experience". In fact, the role of spirituality is very important to understand these paranormal phenomena related to patients at the threshold of death, so as to have an holistic perspective of life and death, as described (for example) in the following book (Olati, 1995):

I asked Sri Aurobindo to show me "Soul Land"...after a long journey, I was very happy with everything that I have seen.... When I got back I looked at the clock and I wondered why the hands were in the same position as they had been when we started. Sri Aurobindo said that our journey was not bound by time; it had taken place in the Infinite, beyond time or space.

This kind of spiritual knowledge (wisdom) could enable health professionals (and all people in general) to realize conveniently this kind of "unusual" experiences to all who has received "the last farewell embrace on the deathbed". Finally, in the "Bibliography" (pp. 163-188), the author mentions the most important references on each of the topics of the chapters covered throughout this book, demonstrating to have a deep knowledge on the theme in question.

\section{Conclusions}

In conclusion, I recommend this book for all those who are interested in the theme on the patients at the threshold of death, and the "paranormal" phenomena linked to them because it is indisputably an important reference on the literature review on the subject in question which might contribute for the construction of a future biomedical model, where the human being might be studied and healed in its various dimensions: physical/biological, psychological, and spiritual. Despite this, I think that some complementary bibliography could have been mentioned by the author, in order to interconnect the subject of the book with the study of "anomalous" phenomena when the patients are in the threshold of death, such as "consciousness and its modified or altered states" (Hayes, 2000) and whose articles and books mentioned above have sought to be a contribution to clarify the theme.

\section{References}

Alexander, E. (2013). Uma prova do céu. Rio de Janeiro, Brasil: Editora Sextante.

Domingos, M., Loução, P., \& Dias, P. (2009). Experiências de quase-morte. Lisbon, Portugal: Ésquilo Editores.

Hayes, N. (2000). Foundations of psychology. Connecticut, US: Thomson Learning.

Martins, P. (2019). Ciência e a Teoria da "Vida após a Morte": Algumas considerações sobre a filosofia da ética. Retrieved from http://ctec.ufp.pt/wp-content/uploads/2019/04/ConsCi\%C3\%AAncias_6-1.pdf

Newton, M. (2000). Destiny of souls. St. Paul, Minn.: Llewellyn Publications.

Olati, A. (1995). The Mother. United States: Mother Meera Foundation.

Tucker, J. (2005). Life before life: A scientific investigation of children's memories of previous lives. New York: St. Martin's Press. 